\title{
COORDENADAS INTELECTUALES DE ÁlVARO ALSOGARAY
}

\author{
PABLO GUIDO*
}

Resumen: El artículo enumera las distintas fuentes de donde se nutrió el pensamiento económico y político de Álvaro Alsogaray, cuya actuación pública en Argentina se desarrolló durante toda la segunda mitad del siglo XX. Alsogaray tuvo un perfil poco usual para su país, ya que no sólo fue un estudioso de las ideas liberales sino que además las intentó llevar a la práctica en el campo de la acción pública. Desempeñó, a lo largo de su vida, diversas actividades: militar, empresario, político, ministro, embajador, legislador y consultor económico, entre las más importantes. En un contexto donde las ideas liberales eran mayoritariamente rechazadas por la población y la dirección política, sindical y empresarial del país, Alsogaray fue reconocido por mantener a lo largo de su vida una misma línea de pensamiento.

Palabras clave: Liberalismo moderno; Economía Social de Mercado; Escuela Austriaca; Ordoliberalismo; Inflación; Rueff; Hayek.

Clasificación JEL: B; B2; B3.

Abstract: The article enumerates the different sources wherefrom there was nourished Álvaro Alsogaray's economic and political thought, whose public action in Argentina developed during the whole second half of the $20^{\text {th }}$ century. Alsogaray had an unusual profile next to his fellow citizen, since not only he was a specialist of the liberal ideas but in addition he tried to put them in practice in the field of the public action. He performed, along his life, in diverse activities: captain in the Armed Forces, businessman, politician, government minister, ambassador, legislator and economic consultant, among the most important tasks. In a context where the liberal ideas were rejected for the most part by the population and the political, union and managerial leadership of the country, Alsogaray was recognized for supporting along his life the same line of thought.

* Doctor en Economía por la Universidad Rey Juan Carlos. Profesor titular de ESEADE (Argentina).

Procesos de Mercado: Revista Europea de Economía Política Vol. VIII, n.ํ 1, Primavera 2011, pp. 209 a 252 
Key words: Modern liberalism; Social Market Economy; Austrian School; Ordoliberalism; Inflation; Rueff; Hayek.

JEL Classification: B; B2; B3.

I

\section{SÍNTESIS BIOGRÁFICA}

Los obstáculos están para vencerlos y no para dejarse detener por ellos.

Álvaro Carlos Alsogaray

El Capitán Ingeniero Álvaro Alsogaray nació en $1913^{1}$ y falleció en 2005, período en el cual la Argentina pasó de ser un país con indicadores económicos y sociales similares a los de las naciones más desarrolladas a uno en franca decadencia. ${ }^{2}$

Habiendo sido el cadete con las mejores calificaciones de la historia argentina durante sus estudios en el Colegio Militar de la Nación, ${ }^{3}$ se retiró de las Fuerzas Armadas con 33 años con el grado de capitán - para ese momento también era Ingeniero Militar ${ }^{4}$ e Ingeniero Aeronáutico Civil ${ }^{5}$ — e inició una carrera empresarial que le ocuparía en diversas áreas (transporte aerocomercial, molinos aceiteros, astilleros, siderurgia y frigoríficos, entre las más relevantes). Si bien su primer cargo público fue, entre fines de 1947 y principios de 1948, como director de la Flota Aérea Mercante Argentina (FAMA), comenzó a cobrar protagonismo en la vida política argentina después del golpe de estado a Juan

${ }^{1}$ Alsogaray era la séptima generación de la familia en territorio argentino, originaria de Navarra (España).

2 «[...] Argentina llegó a tener un PIB por habitante cercano al de los países del Primer Mundo [...]». De Pablo, (2010, p. 52).

3 Esto valió que se le otorgara, durante los cuatro años de formación, el honor de conducir la bandera nacional, caso inédito en la historia argentina. Además obtuvo los premios Pro Patria, Círculo Militar y Bartolomé Mitre durante su paso por el Colegio Militar.

4 Se graduó en la Escuela Superior Técnica del Ejército.

5 Título que obtuvo en la Universidad Nacional de Córdoba, siendo todavía militar en actividad, en 1943. 
Domingo Perón en 1955. Alsogaray ocupó diversos cargos como funcionario: Subsecretario de Comercio (6/10/55 al 16/11/55) en el gobierno del presidente Eduardo Lonardi; Ministro de Industria (16/11/55 al 7/6/56) del presidente Aramburu; Ministro de Economía y Trabajo (22/6/59 al 24/5/61) del gobierno de Arturo Frondizi; Ministro de Economía (27/5/62 al 7/12/62) del gobierno de José María Guido; y embajador en los Estados Unidos (agosto de 1966 a octubre de 1968) del gobierno de Juan Carlos Onganía. Entre 1983 y 1999, de manera ininterrumpida, ocuparía un escaño de diputado en el Congreso Nacional, siendo reelegido en tres oportunidades (1987, 1991 y 1995).

Alsogaray fue fundador de varios partidos políticos: en 1957 del Partido Cívico Independiente, en 1965 de Reconstrucción Nacional, en 1971 de Nueva Fuerza y, por último, de la Unión de Centro Democrático en 1982. Por este último partido, la UCeDé, fue candidato a presidente dos veces, en 1983 y 1989, siendo en esta segunda oportunidad el tercer candidato más votado a nivel nacional.

A principios de 1965 Alsogaray creó el Instituto de la Economía Social de Mercado, dedicado a la elaboración de políticas públicas y a difundir el ideario del pensamiento «liberal moderno» —así lo llamaba Alsogaray- en la Argentina. En 1969 fue elegido académico de número, por la Academia Nacional de Ciencias Económicas de la Argentina, y en 1991 habría de ser elegido también miembro de la Academia Nacional de Ciencias Empresariales. Ingresó como miembro pleno de la Mont Pelerin Society en el año 1970 y en febrero de 1985 la Universidad Francisco Marroquín lo honró con el doctorado honoris causa en el área de Ciencia Política.

Murió el $1^{\circ}$ de abril de 2005 a los 91 años de edad. El diario más importante del país especializado en economía y finanzas, Ámbito Financiero, hizo el siguiente comentario en su publicación del 4 de abril: "A Álvaro Alsogaray, si tuviera que definírselo con un concepto podría ser éste: nadie como él en la historia nacional les enseñó tanto a los argentinos a pensar en términos de libertad». 


\section{II CONTEXTO HISTÓRICO}

Durante el gobierno de Juan Domingo Perón (1946-1955) el llamado modelo de industrialización por sustitución de importaciones (ISI) se terminó de consolidar en Argentina. A lo largo de las primeras cuatro décadas de la segunda mitad del siglo XX aquella «estrategia de crecimiento hacia adentro» fue mantenida prácticamente sin interrupciones ni alteraciones significativas por los gobiernos que sucedieron a la gestión peronista, ya fueran aquellos administraciones civiles o militares. Durante todo el período mencionado los constantes desequilibrios fiscales llevarían a los sucesivos gobiernos, civiles y militares por igual, a buscar soluciones inestables de corto plazo (endeudamiento externo e interno, incremento de la carga tributaria o emisión monetaria) para financiar el creciente y elevado gasto público, conduciendo irremediablemente al país a cíclicas crisis económicas. ${ }^{6}$ La utilización descontrolada de la emisión monetaria por parte del banco central para financiar al sector público argentino condujo a una constante y creciente depreciación de la moneda local, ${ }^{7}$ hasta finalizar en la explosión hiperinflacionaria de 1989. La ISI condujo, simultáneamente, a un proceso de pérdida significativa de la competitividad de la economía argentina, no sólo como consecuencia de los mencionados problemas fiscales, sino por la falta de inversiones suficientes para mantener los altos niveles de ingresos que los habitantes del país habían logrado alcanzar a comienzos del siglo XX. ${ }^{8}$

También durante aquella segunda mitad del siglo XX los argentinos vivieron bajo el dominio de dos péndulos de naturaleza política: el primero, el cívico-militar, representando los ciclos de gobiernos democráticos-militares-democráticos; y el segundo, el peronista-antiperonista, que reveló no sólo la división

${ }^{6}$ Dice el economista argentino Juan Carlos de Pablo: «[...] más que un país cíclico, Argentina es un país ciclónico». En de Pablo (2005, p. 623). Ver también Cerro y Meloni (2003).

7 Entre 1969 y 1991 hubo cuatro cambios de signo monetario.

8 En 1913 el ingreso per cápita argentino en relación al de Australia, Canadá, Gran Bretaña y EE.UU. era del 59\%, 79\%, 77\% y 63\% respectivamente. Cortés Conde (1997, p. 29). 
partidaria y electoral en mitades casi iguales de la sociedad argentina, sino fundamentalmente posiciones irreductibles y enfrentadas al punto de considerarse recíprocamente enemigas una de otra. Esta encrucijada política finalizaría en 1983, después de un gobierno militar, con la asunción de Raúl Alfonsín, que fue el primer candidato presidencial que derrotó al partido peronista en elecciones limpias y sin ningún tipo de proscripciones. ${ }^{9}$

Finalmente, al terminar los años ochenta, después de casi cuatro décadas de evidente desgaste y agotamiento del modelo de sustitución de importaciones, se llegó en Argentina a una situación terminal en materia económica y a una virtual quiebra del Estado que tuvo como su mayor consecuencia a la hiperinflación en $1989 .{ }^{10}$ La gestión de gobierno del presidente Carlos Menem, en la década del noventa, significó para el país un intento concreto - aunque inconsistente y parcial- de modificar las instituciones económicas de la sociedad: reformas monetarias, reformas en el sistema de previsión social, apertura comercial, liberación de precios y desregulación de actividades y privatizaciones, entre las más relevantes, fueron configurando lo que posteriormente se llamaría el Plan de Convertibilidad. Dicho proceso de reformas finalizaría hacia fines del siglo pasado cuando la economía argentina cayó en una de sus típicas y recurrentes crisis fiscales que la llevarían hacia el año 2002, a sufrir no sólo una caída del PIB del $11 \%$ sino además una tasa de desempleo mayor al 20\% y un nivel de pobreza que superó el $50 \%$ de la población total.

Podríamos afirmar que como consecuencia del contexto descrito en los párrafos anteriores Alsogaray decidió abandonar, hacia 1955, sus actividades empresariales para dedicarse al campo de la política y tratar de influir, de manera directa o indirecta y por múltiples medios, en el curso de los acontecimientos para cambiar la decadente situación del país.

9 Entre 1955 y 1973 se realizaron dos elecciones presidenciales en las cuales el partido peronista estuvo proscripto y no pudo participar. En 1973, habiéndose permitido la participación de Perón en las elecciones presidenciales, nuevamente gana por abrumadora mayoría las mismas el partido peronista.

${ }^{10}$ El índice de precios al consumidor aumentó en 1989 un 4,900\%. Solanet (2006, p. 13). 


\title{
III \\ IDEAS ECONÓMICAS Y POLÍTICAS DE ALSOGARAY
}

\author{
Ninguna acción práctica puede emprenderse \\ sin el sostén o la base de una teoría.
}

Álvaro Alsogaray, 1969

De Álvaro Alsogaray podría decirse que fue un auténtico autodidacta gracias a las lecturas de las obras que más influirían sobre su pensamiento económico y político. La formación académica que tuvo tanto en el Colegio Militar como en la Universidad de Córdoba no permite inferir que haya sido en dichos ámbitos donde Alsogaray haya tomado contacto con las ideas liberales. ${ }^{11}$

Alsogaray se ubicaba, según sus propias palabras, en la corriente que denominaba liberalismo moderno, diferenciándola de las corrientes colectivistas como el socialismo, marxismo, nacional socialismo y fascismo, pero también de lo que él consideraba el liberalismo del siglo XIX, el laissez-faire o liberalismo manchesteriano. Alsogaray declaraba a principios de los años noventa que el liberalismo, como sistema de ideas, había tenido dos roles en su vida:

Por un lado me sirvió de guía durante toda mi actuación pública. Por otro, constituyó el leit motiv de dicha actuación, y —si se quiere- de mi lucha durante más de 35 años, que tuvo como objetivo fundamental e indeclinable promover el resurgimiento de esa doctrina en el país y, a través de ello, encaminar a la Argentina hacia mejores destinos. ${ }^{12}$

Los autores preferidos y que tuvieron una influencia fundamental sobre el pensamiento de Alsogaray fueron los principales referentes de la escuela austriaca de economía y del ordoliberalismo alemán: ${ }^{13}$ Mises, Hayek, Eucken, Röepke y Erhard ${ }^{14}$. También

\footnotetext{
11 Ver Sebreli (2004).

12 Álvaro Alsogaray (1993, p. 7).

13 El grupo de alemanes pertenecientes a la llamada Economía Social de Mercado.

14 Ver Unión del Centro Democrático (1983, pp. 10-11).
} 
formaban parte de sus preferidos, en un segundo escalón, Einaudi, Friedman, Machlup y Sennholz. Juan Bautista Alberdi —el «padre intelectual» de la Constitución argentina de 1853- fue también otro de los referentes fundamentales para Alsogaray. Pero, sin duda, era a Jacques Rueff al que Alsogaray reconocería permanentemente como el economista más influyente sobre sus ideas, por encima del resto de los anteriores autores. ${ }^{15}$ La devoción intelectual que Alsogaray tenía hacia todos aquellos intelectuales era de público reconocimiento, como lo demuestran las palabras del Dr. José Heriberto Martínez en el acto de incorporación de Alsogaray como miembro de la Academia Nacional de Ciencias Económicas en 1969:

Viene al seno de nuestra Academia el Ing. Alsogaray con la compañía intelectual de Friedrich von Hayek, Wilhelm Röpke, Ludwig Erhard, Luigi Einaudi, Ludwig von Mises y Jacques Rueff [...].16

Los siguientes son los ejes de pensamiento de Álvaro Alsogaray que mantendría y promovería, por diversas vías, durante sus cincuenta años de actividad pública.

\section{El liberalismo y la Economía Social de Mercado}

¿A qué se refería concreta y específicamente Alsogaray al considerarse partidario y defensor del «liberalismo moderno»? Según el Ingeniero, el liberalismo podía dividirse en dos versiones, una antigua y otra moderna. La primera, elaborada en los siglos XVIII y XIX, conocida con el nombre de capitalismo liberal, liberalismo absoluto, ${ }^{17}$ «liberalismo manchesteriano o política de laissezfaire, laissez-passer». ${ }^{18}$ La segunda, si bien sustentada en los

15 Álvaro Alsogaray (1993, p. 10): «Pero es tal vez Rueff el que más ha influido en mi manera de razonar y de ir al fondo de los problemas. Su lógica es de una incomparable precisión y riqueza intelectual».

16 Academia Nacional de Ciencias Económicas (1969, p. 8).

17 Alsogaray (1968, p. 14).

18 Alsogaray (1993, p. 370). Alsogaray identificaba a los defensores del «liberalismo manchesteriano» como «fundamentalistas del mercado». 
principios de la versión anterior, había sido «reelaborada entre las dos grandes guerras mundiales». ${ }^{19}$ Los fundamentos teóricos de esta nueva versión del liberalismo había que encontrarlos, según Alsogaray, en los trabajos de la segunda década del siglo XX como los de Edwin Cannan, Ludwig von Mises y Frank Knight. ${ }^{20}$ La lista de los miembros de este nuevo movimiento intelectual —así era identificado por Alsogaray- se completaba fundamentalmente con Lionel Robbins, Gottfried von Haberler, Fritz Machlup, Walter Eucken, Friedrich von Hayek, Wilhelm Röpke, Alfred Müller-Armack, Ludwig Erhard, Jacques Rueff y Luigi Einaudi. ${ }^{21}$ Para Alsogaray, todos aquellos pensadores integraban un nuevo movimiento liberal, siendo la Economía Social de Mercado la corriente moderna del liberalismo más importante de la segunda mitad del siglo XX. ${ }^{22}$ Este sistema u orden socioeconómico - la Economía Social de Mercado- era el que Alsogaray habría de proponer públicamente como el único viable para sacar a la Argentina de su decadencia.

¿Qué era la Economía Social de Mercado? ¿Cuál era su origen? Apenas derrotadas las fuerzas militares nazis el territorio alemán había sido dividido administrativamente en cuatro zonas, una para cada fuerza de ocupación aliada. ${ }^{23}$ Posteriormente, habiendo decidido las fuerzas británicas y norteamericanas fusionarse en una zona económica unificada y traspasar la administración de la misma a manos alemanas, Ludwig Erhard - economista alemán que había sido nombrado en 1945 ministro de Finanzas de Baviera- fue elegido director del Departamento de Economía de la Administración Conjunta de las Zonas Occidentales Ocupadas ${ }^{24}$ el 2 de abril de 1948. Lo que sucedió a partir de ese momento fue la ejecución, impulsada por Erhard, de un programa de liberalización económica en Alemania Occidental, sustentada en las ideas elaboradas por un conjunto de académicos alemanes que

\footnotetext{
19 Alsogaray (1993, p. 8).

20 Alsogaray (1969, p. 23).

21 Ibíd., p. 24.

22 Ibíd., p. 23.

23 Estados Unidos, Unión Soviética, Francia y Gran Bretaña.

24 La zona ocupada por el ejército francés ya había sido incorporada a la administración conjunta norteamericana e inglesa de las regiones de Alemania Occidental.
} 
se conocerían con el nombre de Soziale Marktwirtschaft o Economía Social de Mercado. La reforma económica lanzada por Erhard consistió en una reforma monetaria, la reducción del gasto público y prohibición del déficit fiscal, y la eliminación de los controles de precios y racionamiento de la producción. Los resultados obtenidos de dicha reforma económica no sólo fueron muy positivos sino inmediatos:

En 1948, la producción industrial creció 45\% con respecto al año anterior, y en el quinquenio siguiente, 1949-1953, la tasa de crecimiento de la producción industrial promedió el $20 \%$ anual. En el período 1949-1953 [...] el producto real per cápita aumentó a una tasa promedio de $8 \%$ anual y los salarios se incrementaron a una tasa del 9\% anual [...]. Durante el segundo semestre de 1948, los precios crecieron a una tasa del 2\% mensual; en 1949 y 1950 los indicadores de precios disminuyeron; en 1951 y 1952 los precios aumentaron a una tasa del 5\% anual; en 1953 y 1954 nuevamente hubo deflación de precios, en el resto de la década del 50' la inflación se ubicó en el 1,5\% anual. ${ }^{25}$

El origen de la Economía Social de Mercado tenía dos raíces: los economistas sociólogos neoliberales, como Alexander Rüstow y Wilhelm Röpke, por un lado, y la «Escuela de Friburgo» por el otro. ${ }^{26}$ A este segundo grupo pertenecían académicos de la Universidad de Friburgo como Walter Eucken, Franz Böhm y Hans Grossmann-Doerth, siendo el primero de ellos el líder intelectual de esta corriente de pensamiento. Sin embargo, el creador del término Economía Social de Mercado fue el profesor MüllerArmack, quien luego sería Secretario de Estado del Ministerio Federal de Economía durante la gestión de Ludwig Erhard. Corría el año 1946 cuando Müller-Armack afirmaba que estaban agotadas tanto la «pura economía liberal de mercado» como la «economía dirigida», por lo cual se necesitaba una síntesis política-económica:

\footnotetext{
25 Cerdá Omiste, (1987, p. 205).

26 Lampert (1990, p. 85).
} 
Empleamos el nombre de «economía social de mercado» para designar esta tercera forma político-económica [...] la economía de mercado nos parece indispensable como armazón del orden económico futuro; sólo que éste no debe ser una economía liberal de mercado abandonada a sí misma, sino una economía de mercado orientada conscientemente y en el preciso sentido de la dirección social. ${ }^{27}$

En los mismos términos se refería Álvaro Alsogaray cuando diferenciaba las partes constitutivas de esta «economía de mercado moderna con sentido social»: 28

La denominación «Economía Social de Mercado» [...] contiene dos formulaciones que es conveniente diferenciar: la Economía de Mercado y la Economía Social. La primera, o sea la Economía de Mercado, se refiere a las técnicas para asegurar el más eficiente funcionamiento de la economía dentro del marco de la democracia. La segunda, es decir la Economía Social, se ocupa de los fines y toma en consideración los problemas que afectan a los individuos en su vida dentro de la sociedad, poniendo especial énfasis en la protección y seguridad de los más débiles y menos dotados. ${ }^{29}$

Según Alsogaray, en su primer aspecto, el económico, la Economía Social de Mercado se basaba «fundamentalmente en la aplicación, tan rigurosa como resulta posible, de los mecanismos del mercado [...]». ${ }^{30}$ Para el Ingeniero, el mercado era en definitiva una técnica para el funcionamiento eficiente de la economía, uno de los métodos de planificación de la sociedad. ${ }^{31}$ Así lo definía:

El mercado es el sistema o mecanismo a través del cual los productores y los consumidores se ponen en contacto directa o indirectamente para comprar y vender bienes y servicios a fin de satisfacer sus deseos y necesidades conforme a su propia determinación y

\footnotetext{
27 Müller-Armack (1963, p. 154).

28 [Nueva Fuerza], (1972, p. XXI).

${ }^{29}$ Alsogaray (1968, p. 25).

30 Alsogaray (1969, p. 27).

31 El otro era el de la planificación centralizada.
} 
en condiciones y oportunidad pactadas libremente. Ese sistema o mecanismo no es organizado por nadie sino que surge de los citados requerimientos de los consumidores, de la actividad de los productores que los lleva satisfacer dichos requerimientos con el propósito de obtener un beneficio o lucro personal, de la competencia de los compradores y vendedores entre sí que conduce a la libre determinación de los precios y de una serie de factores, incluso factores psicológicos, que determinan interacciones de la más variada naturaleza. El mercado, accionando por medio de fuerzas invisibles, principalmente a través del mecanismo de los precios, coordina y regula la producción y el consumo de manera tal que en todo momento se produzcan en cantidad y calidad adecuadas los bienes y servicios que el público demanda. Asimismo, determina en cierta forma la ubicación de cada uno dentro de la sociedad en función de su aptitud para satisfacer los requerimientos de sus integrantes. ${ }^{32}$

Alsogaray afirmaba que si se permitía el funcionamiento sin demasiadas restricciones del mercado ${ }^{33}$ se podía resolver «en forma espontánea la mayor parte de los problemas relativos al orden económico-social». ${ }^{34}$ De esta manera, los gobiernos podían, de acuerdo al Ingeniero, dedicarse a resolver los problemas extraeconómicos como la educación, la defensa nacional, la cultura, la salud, la protección de los sectores más débiles de la comunidad, etc.

El segundo aspecto - el alcance social — de esta nueva vertiente liberal era considerado por Alsogaray como la otra característica fundamental del orden representado por la Economía Social de Mercado. Así lo expresaba:

El funcionamiento irrestricto del mercado puede provocar, en determinadas circunstancias, y sobre todo en el período de transición, daños graves a numerosos individuos que estos últimos

32 Alsogaray (1968, p. 28).

33 Posteriormente, en el apartado 3.2 .3 se analizan las intervenciones que el Estado debía realizar sobre la economía según lo expuesto por los defensores de la Economía Social de Mercado.

34 Alsogaray (1968, p. 29). 
no podrían por sí solos sobrellevar. En esos casos el criterio social obliga a intervenir para limitar las fricciones y asperezas que produce el libre juego del mercado.

Ese mismo criterio social y otras consideraciones diversas llegan a definirse a favor de la pequeña y mediana empresa como un medio insustituible para evitar la masificación de la sociedad y preservar los derechos individuales.

El individuo, dentro de la sociedad, está expuesto a determinados riesgos que no puede tampoco, por sí solo, enfrentar. Tal el caso, por ejemplo, de la niñez y la ancianidad desvalidas, de los incapacitados, de la atención de ciertas enfermedades, del acceso a las fuentes de educación y capacitación, etc.

[...] la Economía Social de Mercado, como Economía Social, propicia un mayor acercamiento de los empresarios y asalariados a las tareas de gobierno y también a una mayor participación del personal de las empresas en las decisiones fundamentales que atañen a la marcha de las mismas. En este campo la cuestión de procedimientos es crítica. Aquí nos limitamos a fijar la tendencia sin abrir juicio sobre dichos procedimientos. ${ }^{35}$

El Estado, según la perspectiva de Alsogaray, debía así garantizar y asegurar la provisión de ciertos bienes y servicios a la porción de la población que no podía o no estaba capacitada para obtenerla en el mercado. ${ }^{36}$

\section{La importancia del orden social}

En diciembre de 1946, en el preámbulo a la primera edición alemana del libro Wirtschaftslenkung und Marktwirtschaft (Economía dirigida y Economía de mercado) afirmaba su autor, MüllerArmack, que la «formación de un nuevo orden económico [debía] ser la meta de la política económica alemana del porvenir». ${ }^{37}$ ¿Qué era y en qué consistía el orden económico al cual hacían mención

\footnotetext{
35 Alsogaray (1968, pp. 41-42).

36 Ibíd., p. 42.

37 Müller-Armack (1963, p. 53).
} 
los miembros integrantes del movimiento ordoliberal? ${ }^{38} \mathrm{El}$ concepto de orden económico - que revestía un significado clave en esta corriente de pensamiento- era la forma en que se realizaba concretamente la dirección del proceso económico diario. El orden económico hacía referencia a quién decidía cuáles y cuántos bienes producirse, con qué factores de producción se haría, cuál sería la combinación de recursos productivos, cómo se distribuirían dichos bienes, cuánto y cuándo se ahorraría y en qué se invertirían los recursos ahorrados. En otras palabras, lo que el orden económico debía establecer era la manera de solucionar el problema de quién tendría la responsabilidad de asignar recursos productivos de la manera más eficiente y eficaz posible para satisfacer la mayor cantidad de necesidades. Además, según Walter Eucken, el orden económico integraba y complementaba, a su vez, diversos órdenes parciales,

[...] tanto si se trata de formas establecidas por el Estado, por ejemplo, de política comercial, política de precios o política crediticia, como de formas establecidas por la costumbre [...]. Toda ordenación parcial ha de ser considerada como un elemento integrante de la ordenación económica [...]. La conexión total de este proceso hace necesario contemplar cada acto de política económica en relación con el proceso total y su dirección, por consiguiente, con la ordenación económica. ${ }^{39}$

De la misma manera — continuaba Eucken — que debían estar integrados consistentemente los diversos órdenes que forman parte de la organización económica de un país, lo mismo sucedía para el conjunto de los órdenes económicos, sociales, políticos y legales: «No tiene sentido, en el mundo moderno, estructurar el Estado sin atender a la ordenación económica que se practica; o intentar incluso establecer en la misma Constitución formas políticas

38 Término con el cual también se reconoce a esta corriente liberal alemana de la segunda postguerra; en vinculación con el manifiesto (Ordo Manifesto) que en 1936 publicaron Eucken, Böhm y Grossmann-Doerth criticando a la Escuela Historicista alemana y presentando, a la vez, un programa para recuperar el rol de la teoría económica.

39 Eucken (1963, p. 40). 
y ordenaciones económicas incompatibles. Problemas paralelos se derivan para el ordenamiento jurídico ${ }^{40}$ y, podríamos agregar, para el orden social. La influencia que cada uno de estos órdenes ejercía sobre los otros era recíproca, es decir, no existía «dependencia unilateral de los demás órdenes respecto de la ordenación económica». ${ }^{41}$

Al igual que los economistas ordoliberales, una de las preocupaciones permanentes que mantuvo Alsogaray a lo largo de toda su vida pública fue la de la necesidad de establecer en Argentina un orden socioeconómico adecuado - consistente-, ya que para él la alternativa no era orden o anarquía sino qué clase de orden social debía existir y quién establecía dicho orden. ${ }^{42}$ Alsogaray sostenía que los dirigentes políticos $-\mathrm{y}$ también aquellos que actuaban en otras áreas de la vida pública- necesitaban sólidos fundamentos filosóficos para la actividad que tenían que desarrollar, pero que previamente tenían que preguntarse cuál era el principal problema a resolver:

En mi opinión la respuesta es una sola: el establecimiento de un adecuado orden económico-social. Las cuestiones que dicho orden involucra son sin duda para el hombre de Estado las más absorbentes y generales, tanto más cuanto más elevada es su función. ${ }^{43}$

En una entrevista que le realizaron a mediados de la década de los setenta, Alsogaray, en la misma línea expresada por los ordoliberales alemanes, se refería a este tema en los siguientes términos:

En primer lugar en toda sociedad humana debe haber un cierto orden: no es posible concebirla sin que éste, de una manera u otra, exista. Ese orden global es a su vez la resultante de cuatro órdenes: el jurídico, el social, el económico y el político-estatal. Ninguno de ellos prima sobre los demás. Están estrechamente interrelacionados y se influyen recíprocamente. De manera que, si bien

\footnotetext{
${ }^{40}$ Ibíd., p. 47.

${ }^{41}$ Ibíd., p. 51.

42 Alsogaray (1968, p. 44).

43 Academia Nacional de Ciencias Económicas (1969, p. 18).
} 
podemos analizar por separado esos cuatro órdenes, nunca debemos perder de vista la inexorable interdependencia que existe entre los mismos. La eficacia y cualidades del orden global dependen fundamentalmente del equilibrio entre los distintos órdenes, lo cual constituye otra razón para habituarse a considerar los problemas en su integralidad y no como una parcialidad. ${ }^{44}$

Sin embargo, a pesar de colocar en el mismo nivel a los cuatro órdenes mencionados — jurídico, social, económico y político-, para Alsogaray había tres razones por las cuales habría de situar al orden económico como centro del problema del ordenamiento de la sociedad:

Una de ellas reside en que la economía obedece a leyes naturales, que el hombre puede descubrir y utilizar en su provecho, pero que no puede torcer ni alterar sin sufrir las consecuencias. En los demás campos [el jurídico, el social y el político-estatal] la voluntad humana tiene una mucha mayor libertad de acción, pero no puede desprenderse del ordenamiento económico; inevitablemente debe tomarlo en consideración.

Otra de esas razones es de carácter más directo: la economía ocupa buena parte de la vida diaria de los seres humanos, determina en gran medida la ubicación de cada uno dentro de la estructura social y establece la posibilidad de satisfacer las necesidades o aspiraciones materiales de los individuos.

Una tercera razón para considerar en un lugar predominante al tema económico es que de la naturaleza del sistema que se aplique depende en gran medida el mantenimiento de una sólida disciplina social y de las libertades individuales. ${ }^{45}$

De manera recurrente, en sus escritos e intervenciones orales, Alsogaray sostenía que era muy importante "para un mejor ordenamiento del debate» ${ }^{46}$ la clasificación y posterior identificación de las características de cada uno de los órdenes sociales posibles,

\footnotetext{
44 De Pablo (1977, p. 34).

45 Alsogaray (1989, pp. 21-22)

46 Alsogaray (1993, p. 240).
} 
de las ideologías que los sustentaban y las construcciones políticas resultantes. ${ }^{47}$ ¿Cuáles eran las principales características que identificaban a los diferentes órdenes sociales según Alsogaray? Hacia fines de los años sesenta Alsogaray encontraba que las dos únicas maneras de ordenar la sociedad eran a través de la Planificación centralizada y compulsiva de la economía o por medio de la Planificación a través del mercado. ${ }^{48} \mathrm{El}$ primero -la planificación centralizada - consistía en aquel orden socioeconómico donde la planificación la realiza y aplica el comité o la oficina central de planificación del Estado y «cuyos fines se suponen anteriores y superiores a los del individuo». ${ }^{49}$ En el segundo - la planificación vía el mercado-, el objetivo era que fueran los fines de los individuos los que prevalecieran sobre «los supuestos fines colectivos, cuya representación se atribuye el Estado»; la planificación sería formulada por las fuerzas del mercado y encuadrada en reglas no discriminatorias establecidas por el Estado. ${ }^{50}$ Dentro de la primera alternativa Alsogaray ubicaba a las sociedades de tipo totalitario y colectivista, cuyos principales casos concretos eran el socialismo ortodoxo, el nacional-socialismo y el comunismo. Para la segunda alternativa - las sociedades libres- se encontraban las variantes expresadas en el liberalismo del siglo XIX, el conservadurismo y el liberalismo moderno. ${ }^{51}$ Décadas más tarde Alsogaray identificaría a aquellas dos posiciones contrapuestas, la planificación estatal y la planificación individual, como corrientes o ideologías constructivistas y evolucionistas, respectivamente. ${ }^{52}$ En esta última clasificación de las sociedades Alsogaray reconocía explícitamente la influencia que sobre él había tenido Hayek y su libro La fatal arrogancia, expresando así las diferentes concepciones de la sociedad:

47 Además, Alsogaray sostenía permanentemente que la intercomunicación entre los seres humanos y el verdadero debate dependían de un consenso previo respecto al significado de las palabras, de ahí que los cuadros y gráficos eran una referencia constante en sus escritos para ilustrar de manera más eficaz su pensamiento y reflexiones.

48 Alsogaray (1968, p. 45).

49 Alsogaray (1969, p. 139).

50 Alsogaray (1968, p. 45).

51 Alsogaray (1968, p. 45).

52 Alsogaray (1993, p. 402). 
El «constructivismo» parte del supuesto de que si el hombre ha sido capaz de establecer el orden social existente que permite el desenvolvimiento de las sociedades humanas, ha de ser también capaz de modificar por actos de voluntad ese orden y aun de crear otros nuevos, con el propósito de elevar las condiciones de vida de quienes integran esas sociedades. La corriente «evolucionista» sostiene en cambio que el hombre no tiene esa capacidad de «construir» una sociedad conforme a modelos predeterminados, sino que éstos se van configurando espontáneamente a lo largo de dilatados períodos históricos, en función de un «evolucionismo» no darviniano basado en la razón por un lado y los instintos por otro, desarrollados por aquellos grupos que han tenido más éxito en su lucha por la supervivencia y el progreso. ${ }^{53}$

¿En qué residían las diferencias entre los diversos modelos de sociedades que Alsogaray identificaba? Dentro del género totalitario ubicaba, como se dijo anteriormente, tres variantes: el socialismo ortodoxo, el comunismo y el nacional-socialismo. La similitud entre estas fórmulas residía en la organización colectivista de la sociedad, reflejada en la planificación centralizada de la economía. Las diferencias, entre aquellas variantes totalitarias, estaban puestas en la eliminación legal (el socialismo ortodoxo y el comunismo) o de hecho (nacional-socialismo) de la propiedad privada. Para el caso de las sociedades que se organizaban de acuerdo al principio del individualismo recordemos que Alsogaray distinguía entre el capitalismo liberal histórico, el conservadurismo y el liberalismo moderno. Según el Ingeniero, el problema del liberalismo del siglo XIX — la primera de las fórmulas de este género- residía en la «negativa dogmática y absoluta de aceptar la intervención del Estado en la vida económica», generando así numerosos defectos y abusos que fueron desacreditando el sistema, como por ejemplo, la aceptación por parte del Estado de la formación de monopolios u oligopolios o la falta de objetivos «sociales» dentro de las actividades estatales. La fórmula conservadora tenía la característica de haber abandonado las ideas

${ }^{53}$ Ibíd., p. 401. 
liberales para finalizar aceptando privilegios mediante la existencia de los monopolios, manteniendo así el statu quo político, social y económico y evitando de esta manera la movilidad social. Por último, lo que para Alsogaray era la versión moderna del liberalismo, la Economía Social de Mercado, configuraba una síntesis superadora de las dos anteriores versiones mediante la intervención del Estado en la economía "para trazar el marco de la actividad económica, establecer las reglas de juego, asegurar la competencia, resolver los casos críticos que escapan a las reacciones espontáneas del sistema y, finalmente también, para alcanzar determinados objetivos sociales». ${ }^{54} \mathrm{El}$ origen cronológico de este liberalismo moderno Alsogaray lo situaba en 1947, con la constitución de la Sociedad Mont Pèlerin:

\begin{abstract}
Al término de la Segunda Guerra Mundial, se presentó en las democracias occidentales el vital problema de la reconstrucción moral y material de los países devastados por el conflicto. Un pequeño grupo de esclarecidos estadistas, economistas e intelectuales dieron los fundamentos de las políticas que habrían de resolver este problema. La mayoría de ellos se agruparon en la Sociedad Mont Pèlerin y a través de ésta contribuyeron decisivamente a la salvación de los valores de Occidente. ${ }^{55}$
\end{abstract}

Sin embargo, Alsogaray también reconocía la existencia real de terceras posiciones, órdenes híbridos u órdenes intermedios situados entre la concepción totalitaria y libre de la sociedad. Para estas terceras posiciones Alsogaray consideraba a los socialdemócratas como sus principales exponentes, cuyas características eran ser «más o menos liberales en política y verdaderos socialistas en economía». ${ }^{56}$ En el campo económico ésta posición intermedia estaba representada básicamente por los sistemas económicos dirigistas y desarrollistas basados en las ideas keynesianas y partidarios del Estado benefactor. Los procedimientos en el plano de la política económica a los cuales recurrían estas fórmulas de

\footnotetext{
54 Alsogaray (1969, p. 28).

55 Alsogaray (1989, p. 224).

56 Alsogaray (1968, p. 16).
} 
tercera posición eran el estatismo, el dirigismo y el intervencionismo. ${ }^{57}$ En materia político-partidista ubicaba como principales referentes de estas posiciones intermedias a los partidos liberales progresistas, socialdemócratas, socialistas democráticos, demócratas cristianos y socialcristianos. Si bien estas terceras posiciones existían en la práctica, no eran reconocidas por Alsogaray como fórmulas que pudieran «estructurar, de una manera estable y permanente» el orden socioeconómico debido a que respondían a filosofías o principios opuestos que se mezclaban pretendiendo conseguir soluciones deseables. ${ }^{58}$

\section{Función del Estado. \\ Intervenciones conformes y no conformes}

Cuando Alsogaray hacía referencia a las funciones que debía realizar el Estado se basaba fundamentalmente en el punto de vista de los ordoliberales. Los miembros de dicho movimiento consideraban que el surgimiento del capitalismo y la industrialización había tenido un beneficio muy considerable sobre el hombre común, habiéndole brindado a éste mayores oportunidades para mejorar su nivel de vida de la misma manera que había restringido el poder del gobierno y así despolitizado y privatizado mayores ámbitos en la vida de las personas. Pero los ordoliberales alemanes observaban ciertos defectos inherentes al capitalismo liberal del siglo XIX: la creación de grandes monopolios y cárteles que generaban un abuso del poder privado de las empresas sobre los individuos, el surgimiento de diferencias significativas en términos de ingresos y patrimonios entre individuos y grupos de la sociedad, el congestionamiento de las ciudades como resultado del crecimiento de las grandes industrias o fábricas y el cambio negativo que la nueva forma de vida industrial había generado en las relaciones familiares y tradiciones. Como consecuencia de estas supuestas fallas del liberalismo del siglo XIX tanto Röpke como Eucken y Rüstow — principales

\footnotetext{
57 Ibíd., p. 48.

58 Alsogaray (1969, p. 63).
} 
exponentes del ordoliberalismo- proponían que el Estado interviniera activamente en ciertos aspectos de la vida económica de la sociedad para eliminar o evitar estos aspectos degenerativos del capitalismo. Entre estas funciones se encontraba la de controlar o eliminar los monopolios y cárteles privados y limitar el tamaño de las industrias para evitar la concentración económica, crear mecanismos de redistribución de ingresos y riquezas a través del sistema tributario, implementar regulaciones sobre el medio ambiente y el control estatal sobre los recursos naturales, y ejecutar una planificación urbana y rural como medio de garantizar un equilibrio entre la vida laboral y familiar. También una de las funciones principales del Estado, según los ordoliberales, era proveer de una moneda estable a través de la centralización del control monetario en el banco central. Efectivamente, la estabilidad monetaria era, para los liberales germanos, una condición sine qua non para lograr un orden de mercado estable. ${ }^{59} \mathrm{En}$ definitiva lo que estos economistas y pensadores alemanes proponían era que el Estado interviniera activamente para mantener la competencia, la libre formación de precios y evitar los daños sociales o compensar las externalidades negativas que el mercado pudiera eventualmente generar en ciertos grupos o individuos de la sociedad.

La posición de Alsogaray en lo que concierne a las funciones del Estado puede sintetizarse en el siguiente párrafo, escrito hacia fines de los años sesenta:

[...] la Economía Social de Mercado requiere la intervención del Estado para trazar el marco de la actividad económica, establecer las reglas de juego, asegurar la competencia, resolver los casos críticos que escapan a las reacciones espontáneas del sistema y, finalmente también, para alcanzar determinados objetivos sociales. El Estado no puede ser espectador pasivo frente a ciertos problemas sino que debe intervenir de una manera efectiva y rápida. ${ }^{60}$

59 Ebeling (2003, pp. 235-238).

60 Alsogaray (1969, p. 28). 
$\mathrm{Al}$ igual que los economistas ordoliberales, Alsogaray también creía que el liberalismo del siglo XIX había cometido ciertos errores y generaba algunas perturbaciones económicas que debían ser corregidas por el Estado, ${ }^{61}$ fundamentalmente la formación de monopolios privados con la consecuente reducción de la competencia. La diferencia principal entre el liberalismo del siglo XIX y el liberalismo moderno representado por la Economía Social de Mercado era la aceptación, por este último, de la intervención «activa» del Estado en la sociedad ya que, como Alsogaray decía, el mercado no constituía «la panacea universal. A través del mismo no se puede aspirar a resolver todos los problemas humanos y ni siquiera todos los problemas económicos». ${ }^{62}$ En lo que respecta a los tipos de intervenciones que el Estado podía realizar Alsogaray seguía la distinción formulada por Röpke: ${ }^{63}$ había intervenciones conformes e intervenciones no conformes por parte del Estado en la actividad económica. ¿En qué consistía cada una de ellas? Las primeras eran las intervenciones que el Estado debía establecer para defender o mantener las leyes del mercado, asegurando «el libre juego del mercado, en particular de la competencia», ${ }^{64}$ leyes contra los monopolios y cárteles, por ejemplo. Estas intervenciones conformes se referían a la eliminación de «todas las interferencias, rigideces y obstáculos que impiden el libre juego de la competencia y del mercado. Tienden, por lo tanto, a liberar las energías individuales y con ello conducen a la libertad». ${ }^{65}$ Las intervenciones no conformes eran aquellas que trataban de solucionar los problemas mediante una acción directa o dirigista en contra de las leyes del mercado como los controles de precios y salarios, restricciones a la competencia, leyes de alquileres, etc. En otras palabras, para Alsogaray la intervención del Estado

61 Alsogaray se refería en estos términos a esa etapa del liberalismo: «economía liberal del siglo XIX», «economía manchesteriana», «sistema de laissez-faire»o «liberalismo absoluto».

62 Alsogaray (1969, pp. 27-28)

${ }^{63}$ Röpke (1949, p. 34).

64 Alsogaray (1969, p. 153).

65 Alsogaray (1969, p. 154). 
[...] no debe estar dirigida nunca contra las leyes del mercado, sino que debe ser conforme a dichas leyes. No se trata del quantum de intervención aceptable o recomendable, sino de la naturaleza de dicha intervención. ${ }^{66}$

El propio Alsogaray, sin embargo, reconocería décadas más tarde, hacia mediados de los años noventa, que el límite de las intervenciones conformes era difícil de precisar pero que debía «ubicarse en el punto en que crean ineficiencias económicas que conspiran» contra la competencia y el funcionamiento del sistema de precios. ${ }^{67}$

Dentro de las funciones concretas y específicas del Estado que Alsogaray apoyaba estaban la de asegurar el respeto a la propiedad privada, garantizar la estabilidad monetaria y establecer las condiciones para que operara la competencia efectiva a través del combate a los monopolios y la eliminación de las barreras burocráticas que dificultasen aquella. ${ }^{68} \mathrm{Si}$ bien el Ingeniero rechazaba en términos generales los privilegios que pudieran otorgarse a determinadas empresas o actividades, aceptaba al igual que los economistas ordoliberales la promoción estatal de las pequeñas y medianas empresas con el objetivo de mantener ciertas tradiciones y relaciones sociales y familiares.

¿Cuál era la posición de Alsogaray respecto de las empresas estatales? Él mencionaba que la Economía Social de Mercado

[...] no adopta una actitud dogmática contra las empresas del Estado. Se opone sí al estatismo, es decir, a la tendencia de absorber cada vez más actividades económicas a través de empresas del Estado con la excusa de que así lo exige el interés general o por simples consideraciones ideológicas. Desde el punto de vista de la economía de mercado no importa tanto quién es el propietario de la empresa; lo decisivo es que esta última funcione dentro del mercado, es decir, sometida a las reglas de la competencia, de la libre formación de los precios, de la oferta y la demanda,

\footnotetext{
66 Ibíd., pp. 28-29.

67 Alsogaray (1993, pp. 370-371).

68 Alsogaray (1968, pp. 30-31)
} 
etc. Por el hecho de que el propietario sea el Estado la empresa no debe gozar de privilegio alguno, debiendo ajustarse a las mismas normas y leyes que regulan la vida de las demás empresas. ${ }^{69}$

En caso de que por su característica natural una actividad tuviera la condición monopólica era necesario establecer la conveniencia de ser estatal o privada, y en caso que la propiedad recayera en el Estado se deberían extremar «las medidas de control para proteger al contribuyente o al usuario, ya que la empresa tenderá a confundir su función con las del Estado mismo». ${ }^{70}$

En lo que respecta al comercio exterior Alsogaray creía - entre las décadas del cincuenta y setenta-que un país debía lograr la mayor industrialización posible y que dicho proceso requeriría al inicio un cierto grado de proteccionismo. Para él la economía de mercado no se oponía a aquella medida siendo que no proponía una libertad tan absoluta como para terminar eliminando definitivamente los aranceles y barreras comerciales. Lo más conveniente, según Alsogaray, sería que el Estado estableciera

[...] niveles razonables de protección, de carácter no discriminatorio, para que los empresarios instalen aquellas fábricas o emprendan aquellas actividades que puedan funcionar dentro de esos niveles. Además debe fijarse una escala decreciente, a lo largo de un cierto número de años, para ir disminuyendo paulatinamente la protección de manera de aproximarse cada vez más a los precios internacionales. ${ }^{71}$

Respecto a la distribución del ingreso Alsogaray sostenía que si bien debía ser equitativa tenía que estar "condicionada al esfuerzo que hace cada uno».72 Para lograr este objetivo había dos vías complementarias:

La primera de ellas se deriva de la naturaleza misma de la economía de mercado que tiende espontáneamente a distribuir los

\footnotetext{
69 Alsogaray (1968, p. 36).

70 Ibíd.

71 Alsogaray (1968, p. 37).

72 [Nueva Fuerza], (1972, p. XVIII).
} 
ingresos en forma muy amplia entre sectores cada vez más numerosos de la población. Así es que en los países donde se practica la Economía Social de Mercado el ingreso correspondiente a los trabajadores con relación al del capital, es mucho mayor que al que existe en países donde se aplican otras economías. Pero cuando esa «distribución espontánea» no alcanza los niveles deseados o se producen perturbaciones de cualquier orden, siempre queda el recurso de que el Estado intervenga supletoria y complementariamente para mejorar esa «distribución». De cualquier manera la Economía Social de Mercado tiene una característica que no poseen las otras: produce abundancia y entonces hay algo para distribuir. Las demás sólo producen escaseces y necesidades; por lo tanto es inútil hablar de una mejor distribución [...]. Lo que realmente tiene importancia [...] es hablar de «igualdad de oportunidades» para todos aquellos que tengan deseos de progresar. ${ }^{73}$

Alsogaray afirmaba que el error de los socialistas y de los socialdemócratas consistía en creer que la riqueza era un don divino que simplemente «existía» y que lo único que debían hacer los Estados era simplemente redistribuirlo equitativamente: «la riqueza hay que producirla y ello implica un trabajo y un esfuerzo [...]». ${ }^{74}$

En síntesis, según Alsogaray, el Estado debía asegurar el buen funcionamiento de la economía de mercado para de esa manera poder dedicarse a aquellas funciones en las cuales el sector privado no podía intervenir: la salud y educación pública, la defensa nacional, la administración de justicia, la seguridad social y la infraestructura. ${ }^{75}$

\section{La batalla contra el socialismo: Hayek y Camino de Servidumbre}

Alsogaray siempre repetía que el libro Camino de Servidumbre, escrito por Friedrich Hayek, había configurado un punto de quiebre

\footnotetext{
73 [Nueva Fuerza], (1972, p. XVIII).

${ }^{74}$ Ibíd., p. XIX.

75 Academia Nacional de Ciencias Económicas (1969, p. 49).
} 
en su vida personal e intelectual: ${ }^{76}$ «[...] fue para mí una verdadera revelación y más tarde una guía segura en la lucha que me tocó enfrentar». ${ }^{77}$

Camino de servidumbre era un mensaje de alerta, una advertencia en la cual Hayek afirmaba que «si no se atendía a las tendencias totalitaristas inherentes al proceso de planificación central de las economías y las sociedades, el fatídico destino de Rusia y Alemania sería también el de Inglaterra». ${ }^{78}$ ¿Por qué la planificación económica centralizada se traduciría en un totalitarismo político, convirtiendo así al ser humano en prácticamente un esclavo bajo el régimen socialista? ¿Por qué surgía, según Hayek, un conflicto natural entre el colectivismo y la libertad individual? En primer lugar, para Hayek, la planificación económica al tener que abarcar todos los fines individuales y lograr configurar un plan coherente tenía que colocarse «en manos de expertos, funcionarios permanentes u organismos autónomos» ${ }^{79}$ generando así la necesidad de eliminar el sistema de decisión por mayorías por ser inadecuado a dichos objetivos. En segundo lugar, bajo un gobierno arbitrario y discrecional, propio de la planificación centralizada, el Estado de Derecho ${ }^{80}$ desaparecería, generándose entonces dos consecuencias: por un lado, el planificador necesariamente tomaría decisiones discriminatorias respecto a las necesidades particulares de cada persona, privilegiando a unas en contra de otras; por otro lado, no pudiendo las personas prever las acciones del Estado se generaría una mayor incertidumbre y un mayor riesgo en las propias decisiones. En definitiva, la inexistencia del Estado de Derecho configuraba un gobierno arbitrario dada la falta de límites a los poderes del Estado y la inexistencia de normas preestablecidas para la acción del mismo. En tercer y último

76 Según María Julia Alsogaray, su padre se refería a Camino de Servidumbre como el «Camino de Damasco, una verdad interior que hasta ese momento no había podido expresar de esa manera». En Entrevista a María Julia Alsogaray (31 de julio y 3 de octubre de 2007).

77 Alsogaray (1993, pp. 8-9).

78 Hayek (1997, pp. 22-23)

79 Hayek (1990, p. 93).

80 Para Hayek el Estado de Derecho consistía en un sistema de leyes generales, abstractas, ciertas e igualitarias. En Hayek (1982, pp. 290 y 292). 
lugar, Hayek afirmaba que la planificación económica centralizada suponía la pérdida del control individual no sólo sobre los objetivos económicos sino sobre todos los objetivos personales:

La autoridad directora de la actividad económica intervendría no sólo la parte de nuestras vidas que afecta a las cosas inferiores: intervendría en la asignación de los medios limitados con que contamos para todas nuestras finalidades. Y quien controla toda la vida económica, controla los medios para todos nuestros fines y, por consiguiente, decide cuáles de éstos han de ser satisfechos y cuáles no [...]. El control económico no es sólo intervención de un sector de la vida humana que puede separarse del resto; es el control de los medios que sirven a todos nuestros fines, y quien tenga la intervención total de los medios determinará también a qué fines se destinarán, qué valores serán calificados como más altos y cuáles como más bajos: en resumen, qué deberán amar y procurarse los hombres. ${ }^{81}$

Es así que para Hayek las buenas intenciones de ciertos socialistas, políticamente no totalitarios, tenían un desenlace no intencionado e involuntario: el objetivo de planificar la economía desataba otros fenómenos que conducían finalmente al totalitarismo, a la tiranía y a la destrucción de todas las libertades. En síntesis, el mensaje hayekiano en esta obra de 1944 consistía en afirmar la incompatibilidad entre el socialismo y la libertad, y advertir sobre los peligros que la planificación económica centralizada tendría sobre las libertades individuales. ${ }^{82}$

¿Por qué Camino de servidumbre fue clave, entonces, para la vida de Alsogaray? Por un lado, porque fue aquel texto el que lo habría decidido a comenzar a estudiar economía («[...] me indujo al estudio de los sistemas económicos como factor decisivo del orden social» diría Alsogaray). ${ }^{83}$ Por otro lado, por la conexión y similitud que Alsogaray encontró entre la tesis de Hayek y la situación política de Argentina en la segunda mitad del siglo XX:

\footnotetext{
81 Ibíd., p. 125).

82 Ebenstein (2001, pp. 114-127)

83 Todo es Historia (1995, p. 77).
} 
La advertencia de Hayek, a la luz de lo que estaba ocurriendo en la Argentina en 1945-1946 y los primeros y cada vez más drásticos avances de Perón sobre la economía privada, fue para mí una verdadera revelación y me llevó a examinar al peronismo desde ese ángulo. Hoy creo más que nunca en la validez de aquella tesis. El totalitarismo económico engendra el totalitarismo político. No puede haber verdaderas libertades individuales si no hay libertad económica. ${ }^{84}$

Para Alsogaray el régimen peronista era un «definido intento nacional-socialista cuya configuración y evolución se ajustaba rigurosamente al pronóstico de Hayek». ${ }^{85} \mathrm{El}$ peronismo era, para el Ingeniero, el «gran culpable de la decadencia argentina y del deterioro moral y material de las condiciones de vida» ${ }^{86}$ de los argentinos. Además, el avance estatal sobre la actividad privada a través de diversos mecanismos del régimen peronista era observado por Alsogaray como la causa principal del problema inflacionario argentino:

$\mathrm{Al}$ estatizar las principales actividades y empresas y regular toda la economía, el Estado se ve en la necesidad de crear vastos organismos de administración y control, lo cual da origen a una dominante burocracia [...]. El financiamiento de esa burocracia y las ingentes pérdidas que siempre origina la administración estatal de emprendimientos económicos, generan un fuerte déficit que no puede ser atendido con la recaudación normal de impuestos [...]. Se recurre entonces a la expansión artificiosa del crédito y a la emisión de moneda, que constituyen la causa directa de la inflación. ${ }^{87}$

La inflación, según Alsogaray, era a su vez un factor determinante en la Argentina para el surgimiento del totalitarismo político durante el gobierno peronista: al intentar ocultarse los efectos

\footnotetext{
84 Alsogaray (1993, p. 22).

85 Ibíd., p. 23.

86 Ibíd., p. 25.

87 Ibíd., p. 24.
} 
inflacionarios mediante controles de precios en todos los mercados se originaba la inflación reprimida, lo cual tenía un traumático desenlace que se observaba en violentas devaluaciones con «explosión» de precios como reflejo del reajuste al que obliga dicho proceso inflacionario. Los efectos de aquellos procesos, de acuerdo a la visión de Alsogaray, no se circunscribían al área económica sino que también se extendían al ámbito político:

En primer lugar porque se requiere una acción política para hacer cumplir compulsivamente el mandato de los planificadores económicos. Después, para acallar las protestas y aplastar las reacciones que ese mandato siempre suscita [...]. Los controles iniciales fueron requiriendo cada vez más fiscalización, hasta llegar a un completo autoritarismo económico. Este necesitó también un creciente autoritarismo político, con lo que el país se deslizó hacia la dictadura. ${ }^{88}$

Alsogaray sostuvo persistentemente que, a pesar del golpe de estado realizado al gobierno de Perón en 1955, el régimen socioeconómico plasmado definitivamente en el peronismo a la salida de la Segunda Guerra Mundial se había mantenido incólume en el país a lo largo de las décadas siguientes. Alsogaray siempre sostuvo que había que eliminar el régimen socioeconómico peronista (caracterizado por el estatismo, intervencionismo, desarrollismo y la inflación) para poder regresar al sistema republicano de gobierno y a una economía de mercado tal cual era considerada en los principios de la Constitución Nacional de 1853. A principios del año 2004, quince meses antes de fallecer, Alsogaray afirmaba en una entrevista:

Sigo pensando que el peronismo es una versión criolla del nacionalsocialismo. No en sentido político [...]. Pero hablando técnicamente, el peronismo es nacionalsocialismo; un nacionalismo cerrado que pone una barrera hacia el exterior, y un socialismo práctico por la forma de conducir la economía y la estructura social

88 Alsogaray (1993, p. 25). 
del país [...] Perón gobierna dictatorialmente. Es un verdadero dictador en el país bajo apariencias democráticas. ${ }^{89}$

En consecuencia, Alsogaray también siempre afirmó que el golpe de estado de 1955 había sido el único justificable en el país dado que la Argentina vivía en aquel entonces un totalitarismo contrario a la Constitución Nacional y en condiciones inaceptables e insostenibles para la población, diferenciándose así del resto de los derrocamientos de los gobiernos civiles liderados formalmente por las fuerzas armadas:

La revolución [de 1955] en sí misma, desde mi punto de vista, fue un acto patriótico [...]. Podemos definir a la Revolución Libertadora como un acto de reivindicación argentina [...] considero que la Revolución Libertadora es el único golpe de estado que está justificado, porque el régimen de Perón era una dictadura y contra eso se tenía que reaccionar. Los demás golpes de Estado han tenido motivos menores y no son justificables [...] la Libertadora fue un acto de sanidad de la población argentina que no quería seguir viviendo bajo la dictadura de Perón. ${ }^{90}$

\section{Teoría monetaria e inflación}

El sistema económico vigente en Argentina, según Alsogaray desde 1946, se caracterizaba por el intervencionismo, el dirigismo y el desarrollismo. El cuarto elemento que acompañaba al régimen económico vigente era el sesgo inflacionario. Así, el debate público y el estudio sobre la cuestión monetaria fue uno de los temas principales a los cuales Alsogaray dedicó su vida. Lograr la comprensión, por parte de la opinión pública en general y de la clase dirigente argentina en particular, de las causas y los efectos de la inflación fue un objetivo que nunca faltaría en su actuar político, en sus escritos o en su participación en los diversos medios de comunicación. Para Alsogaray la estabilidad monetaria

89 Noticias (2004, p. 72).

90 La Nación (2004, p. 5). 
no sólo era una condición necesaria para el funcionamiento de un orden económico eficiente sino que la preservación del valor de la moneda era «un derecho fundamental del individuo», ${ }^{91}$ lo cual revela la motivación de su insistencia en el tema a lo largo de cinco décadas. ¿Qué era la inflación según Alsogaray? ¿Cuáles eran sus causas y cuáles sus efectos? Así lo explicaba en los años sesenta:

Para el hombre de la calle la inflación es simplemente el alza de precios y la elevación del costo de vida [...]. Se le llama así inflación a lo que no es en realidad sino una consecuencia de la misma. Se toma el efecto visible como la causa que lo determina. De ahí la tendencia natural, que los enemigos de la economía de mercado explotan muy fácilmente, a querer contener la inflación mediante artificios inoperantes y hasta contraproducentes como el control de precios, los márgenes de ganancias y otras medidas dirigistas $[\ldots]$.

La inflación consiste en realidad en la creación y puesta a disposición del público de más medios de pago que los que corresponden en un momento y circunstancias dadas a los bienes ofrecidos o, de una manera más general, al nivel de actividad económica existente [...].

Definida así la inflación, es evidente que no constituye un hecho fatal, ni una catástrofe de la naturaleza, ni un castigo divino. Es simplemente el resultado de acciones humanas perfectamente controlables [...].

[...] la ruptura del equilibrio entre los medios de pago y los bienes ofrecidos. Y está en manos de las autoridades responsables oponerse a dichas fuerzas, lo cual no depende de consideraciones técnicas sino de factores morales y políticos.

[...] el remedio parecería obvio e inmediato: reducir dichos medios a la proporción adecuada o, en una etapa anterior, evitar que la excedan. Desgraciadamente, el problema no es tan simple. Una determinación de esa naturaleza está siempre sometida a fuertes presiones políticas y constituye sin duda uno de los más críticos problemas para todo economista u hombre de gobierno. ${ }^{92}$

91 Alsogaray (1993, p. 373).

92 Alsogaray (1969, pp. 85-86). 
Se podría afirmar que todas las ideas que Alsogaray tenía respecto al tema monetario estaban fundamentadas en la teoría que sostenía al respecto Jacques Rueff, asesor del presidente francés de Gaulle hacia finales de los años cincuenta y partícipe directo del programa económico cuyos resultados fueron conocidos como el «milagro francés» por aquella época. Rueff utilizaba, conjuntamente, la ley de Say y la teoría cuantitativa del dinero ${ }^{93}$ como herramientas teóricas para explicar los fenómenos monetarios. Alsogaray lo exponía de la siguiente manera:

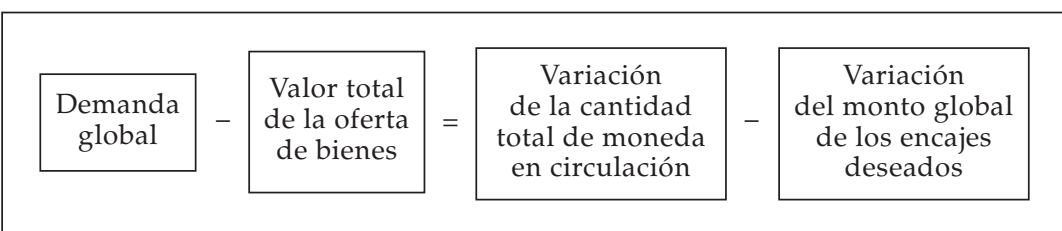

Fuente: Álvaro Alsogaray, Política y Economía en Latinoamérica, Editorial Atlántida, 1969, p. 87.

¿Qué significaba esta fórmula? Si la variación en la oferta monetaria se igualaba a la variación en la demanda deseada de dinero (encajes deseados) ${ }^{94}$ entonces la cantidad de bienes (oferta global) se correspondería al poder de compra de los agentes económicos (demanda global). Se estaría frente a una situación de equilibrio económico general donde los precios se mantendrían estables. Ahora bien, la inflación se generaría cuando dicho equilibrio económico se quebrara al producirse una variación en la oferta monetaria mayor a la de la demanda de dinero: «Para que haya inflación es necesario que el sistema monetario y financiero haga posible que se ejerza una "demanda sin oferta" $\gg$ " 95 . Para Alsogaray era, entonces, el déficit fiscal - y también la expansión crediticia- financiado mediante emisión monetaria del banco

93 «Cette formule conduit à une version révisée de la loi des débouches de JeanBaptiste Say et de la théorie quantitative de la monnaie». En Rueff (1979, p. 84).

$94 \mathrm{El}$ «encaje deseado» estaba integrado por dos componentes: el dinero que se utiliza para los pagos de transacciones realizadas en el mercado y el usado por las personas para enfrentar necesidades eventuales (atesoramiento).

95 Instituto de la Economía Social de Mercado (1984, pp. 3.5-5). 
central la causa última de la inflación, no significando otra cosa «que querer vivir por encima de las posibilidades, lo cual se consigue durante algún tiempo, pero a costa de gravísimos desórdenes en el ordenamiento económico-social» ${ }^{96}$.

Alsogaray reconocía las ventajas - siguiendo el mismo planteo que Rueff- del establecimiento de un sistema de patrón oro como instrumento para alejar la posibilidad de inflación, ${ }^{97}$ si bien este argumento no fue utilizado por el Ingeniero como propuesta de política pública para la Argentina. En consecuencia, Alsogaray proponía una mayor y más amplia difusión entre la población y la opinión pública del conocimiento de las causas y consecuencias del fenómeno inflacionario para obligar a los funcionarios públicos «a apartarse de la demagogia, a prescindir de consideraciones inmediatas de política electoral y tener el coraje civil de adoptar medidas que en muchos casos serán restrictivas y hasta dolorosas». ${ }^{98}$

\section{La democracia}

Alsogaray entendía que la democracia consistía en un sistema político que tenía dos características: por un lado, la defensa de las libertades políticas, entendidas éstas como la libre elección de los gobiernos y una adecuada sustitución y rotación de los mismos; y, por el otro, la de ser un mecanismo para dirimir los conflictos que se planteaban en la sociedad de acuerdo con la voluntad de la mayoría. ${ }^{99} \mathrm{El}$ Ingeniero manifestaba abiertamente su oposición a la existencia de lo que él denominaba las «democracias de masas», es decir, a aquellos gobiernos democráticos

96 Alsogaray (1969, p. 88)

97 «Existen métodos más o menos automáticos y en cierta forma independientes de la voluntad de los funcionarios para regular y mantener el equilibrio entre los medios de pago y los bienes ofrecidos y con ello evitar la inflación. Por ejemplo, cuando se recurre a un método como el patrón oro, o a instituciones financieras y monetarias separadas del poder político que aplican reglas similares a las de aquél [...]». Alsogaray (1969, p. 91).

98 Ibíd., p. 93.

99 Alsogaray (1993, p. 285). 
degradados como consecuencia de la falta de límites al poder para evitar abusos y arbitrariedades por parte del gobierno:

La clave reside en lo que podemos denominar «democracia limitada». Se establecen en ésta restricciones precisas a la acción de las mayorías. Generalmente se lo hace por medio de textos constitucionales. En éstos se fijan los derechos y garantías individuales y se establecen frenos a la acción gubernamental. Esto implica que las legislaturas tampoco son omnímodas, aunque expresen la voluntad de las mayorías. Están sujetas por la Constitución a determinadas limitaciones [...] una democracia ilimitada funciona como una verdadera dictadura que es tan perniciosa como cualquier otra. ${ }^{100}$

En este sentido, Alsogaray se alineaba a la posición que Hayek tenía respecto al mismo tema. ${ }^{101} \mathrm{El}$ siguiente es un fragmento de la entrevista que Alsogaray le realizara en 1977 a Hayek durante la visita de éste último a la Argentina:

- Hayek: Lo que usted llama «democracia de masas» es lo que yo he denominado «democracia» $\mathrm{o}$ - mejor dicho- «gobierno con poderes ilimitados». Esto quiere decir que los gobiernos surgidos de una mayoría electoral, por una deformación del concepto de democracia, se consideran investidos de una autoridad sin límites y de un poder discrecional prácticamente absoluto para hacer todo lo que consideran conveniente hacer. El problema surge de que se da por supuesto que en una democracia los poderes de la mayoría deben ser ilimitados, y que un gobierno con poderes ilimitados debe usarlos para asegurar los intereses de esa mayoría. El gobierno se verá así forzado, para asegurarse el apoyo continuado de esa mayoría, a hacer uso de sus poderes ilimitados en favor de intereses especiales, esto es, de los grupos que la componen,

100 Alsogaray (1993, p. 286).

101 En distintas obras Hayek expuso su preocupación respecto a lo que él denominaba «democracia ilimitada»: «[...] no es el modelo democrático en sí, sino su variante de tipo ilimitado, lo que, en mi opinión, puede llegar a resultar tan opresivo como cualquier otro gobierno arbitrario». Hayek (1985, p. 8); También Hayek (1975) y Hayek (1976). 
tales como comerciantes, sindicatos, habitantes de regiones particulares, etc. Esto es especialmente visible en el terreno económico, en el cual el gobierno se verá obligado a intervenir para complacer a los grupos de la mayoría que desean que se haga una excepción a su favor. En tales condiciones, un partido político que espera alcanzar y mantener el poder apenas tendrá más opción que la de utilizar sus poderes para comprar el apoyo de los grupos particulares [...].

- Alsogaray: Ese razonamiento, que comparto en todos sus tér$\operatorname{minos}[\ldots] .{ }^{102}$

\section{La ideología como herramienta de la acción política. El rechazo al pragmatismo político}

Alsogaray remarcaba habitualmente la necesaria distinción entre dos formas de enfrentar los problemas en la actividad política. Una de ellas era la que se reflejaba en el actuar de los hombres prácticos o pragmáticos:

[...] confían en su habilidad intuitiva para proceder en cada caso conforme a las circunstancias, considerando como una virtud su disposición a adaptarse a cualquier impulso externo. En general, estos hombres asignan muy poco valor a las teorías y no hacen cuestión de métodos. Pueden hoy defender una tesis y mañana precisamente la contraria. ${ }^{103}$

Esta manera de actuar constituía, según la perspectiva de Alsogaray, no sólo una forma de «eludir definiciones comprometedoras» ${ }^{104}$ sino también de «negar el conocimiento y el proceder científico». ${ }^{105} \mathrm{El}$ hombre pragmático, al querer ubicarse en un punto intermedio entre las ideologías socialista y liberal, navegaba sin rumbo preciso. Alsogaray consideraba esta manera

\footnotetext{
102 Somos (1977, pp. 32-33).

103 Academia Nacional de Ciencias Económicas (1969, p. 13).

104 Alsogaray (1993, p. 240).

105 Ibíd., p. 366
} 
de actuar - el pragmatismo- como una actitud indeseable y peligrosa: ${ }^{106}$

Por ello marchan a la deriva, sin rumbo y teniendo constantemente que improvisar con arreglo sólo a su «infusa sabiduría». Atribuyen los fenómenos que tienen a la vista a causas que por regla general nada tienen que ver con ellos. Proceden como los augures de la antigüedad o los brujos de las tribus, considerando como causas a factores tan extraños como el vuelo de los pájaros o el enojo de los dioses. Y en función de tan «científicos» conocimientos, adoptar medidas que en la mayoría de los casos conducen a tremendos fracasos. ${ }^{107}$

La otra manera de actuar era a la que adscribía públicamente Alsogaray y que consistía en mantener y sostener a lo largo del tiempo el mismo conjunto de principios, a pesar del rechazo que pudieran generar dichas ideas en la mayoría de la sociedad: «[...] seguir un rumbo conforme a una teoría adecuada, defender con tenacidad determinados valores morales y orientar y conducir aún a costa de impopularidad y sacrificios en lugar de ceder a las presiones del medio ambiente». 108

La adopción de un sistema consistente de ideas o una buena teoría científica ${ }^{109}$ configuraba así, para el Ingeniero, una guía para la acción política, cumpliendo aquel un papel orientador, aglutinante y coordinador de la actividad política para el hombre de Estado o el economista en funciones públicas. Renegar de las ideologías era actuar «a ciegas», según Alsogaray, ya que existían principios y fundamentos filosóficos «sin los cuales toda acción resulta carente de rumbo y podría engendrar contradicciones y desorden». ${ }^{110}$ En definitiva, la utilización de una eficiente y eficaz teoría científica le ofrecía al hombre de Estado, al político y al

\footnotetext{
106 Academia Nacional de Ciencias Económicas (1969, p. 14).

107 Alsogaray (1993, p. 366).

108 Academia Nacional de Ciencias Económicas (1969, p. 14).

109 Las teorías malas o perniciosas, según Alsogaray, constituían instrumentos políticos al servicio de las malas ideologías.

110 Academia Nacional de Ciencias Económicas (1969, p. 17).
} 
economista, una guía de acción para el establecimiento de un adecuado orden socioeconómico, cuestión de suma importancia en el pensamiento del Ingeniero:

Si las teorías son importantes en el mundo de la física mucho más lo son en el campo de las ciencias del hombre [...]. En las ciencias sociales $[\ldots]$ ni los fenómenos ni los experimentos pueden reproducirse según los deseos del investigador, y además, como hay una íntima e inmediata sucesión entre una nueva teoría y las decisiones que, basadas en ella, se ponen en práctica, cuando se produce un fracaso aparecen consecuencias indeseables y a veces penosas para muchos seres humanos. De ahí que la elección de la teoría sea en este campo tan difícil y tenga tanta importancia. Por un lado su elaboración y comprobación experimental es casi imposible y por otro sus consecuencias pueden ser desgraciadas. De lo cual se desprende que es fundamental no errar en el enfoque teórico. ${ }^{111}$

Como ejemplo de efectos económicos y sociales negativos que surgían como consecuencia de la elección de una teoría errónea Alsogaray mencionaba al socialismo, "cuya aplicación leninista-stalinista costó la vida a millones de seres humanos y la pérdida de libertad a los individuos de más de una generación en varios países». ${ }^{112}$

A fines de 1965 Alsogaray fue invitado por diversas comisiones $^{113}$ de la Cámara de Diputados de la Nación para exponer sobre la situación económica del país. Antes de referirse al contenido del temario para el cual había sido invitado, Alsogaray afirmó -en función de su experiencia personal- la importancia de una orientación doctrinaria en la acción política:

[...] en todo lo que me ha tocado actuar en la vida pública del país lo he hecho siguiendo lo que podríamos llamar una orientación

111 Ibíd., p. 30

112 Ibíd., p. 32.

113 Comisión de Presupuesto y Hacienda, Comisión de Finanzas y Comisión de Relaciones Exteriores y Culto. 
o una doctrina. La ventaja de tener una orientación o una doctrina, si es que la misma es buena, si es que se está convencido de ella y si se tienen los nervios bien templados para que en los momentos difíciles no se dude de ella, es que no hay necesidad de improvisar. Todos los problemas, aunque aparentemente se presenten como distintos uno de otros tiene un denominador común y una ligazón que permite tratarlos con completa coherencia [...].

Yo y el grupo de personas que me acompañaron, para bien o para mal, hemos procedido siempre de acuerdo a una doctrina determinada y no a improvisaciones circunstanciales. Esto no excluye que, en momentos difíciles, uno no tenga que echar mano a recursos no demasiado ortodoxos. No excluye tampoco que a veces haya que hacer ciertas concesiones apartándose de la teoría en función política. Pero lo importante es saber si se está caminando en la buena dirección con firmeza y con el propósito de alcanzar la meta o el objetivo propuesto o si simplemente se está improvisando ante el desconcierto que producen los acontecimientos que se tienen enfrente. Nosotros hemos seguido la teoría en la cual creemos, tanto como nos ha sido posible; y volveríamos a seguirla si las circunstancias nos colocaran otra vez en situación de hacerlo. ${ }^{114}$

\section{El postulado de la tendencia como estrategia de acción política}

El postulado de la tendencia fue una idea sostenida por Alsogaray que hizo explícita y pública por primera vez hacia fines de los años sesenta, en su libro Bases para la acción política futura. Recordemos que Alsogaray afirmaba, por un lado, que los dos únicos modelos que podían constituir un orden social eran aquellos basados en la planificación centralizada o en la planificación del mercado aunque ninguno de ellos podía ser alcanzado de manera absoluta; ${ }^{115}$ por el otro lado, apoyaba a la Economía Social de

114 Tribuna Cívica (1965, p. 1).

115 Alsogaray reconocía que lo que sucedía en la práctica era que las sociedades totalitarias incorporaban elementos de la economía de mercado y las sociedades libres aceptaban algunos métodos provenientes de la planificación centralizada. 
Mercado como la mejor alternativa dentro del orden económico-social liberal, si bien ésta última no podía ser considerada «un modelo abstracto que deba ser alcanzado en forma absoluta [...]».116 Además, el Ingeniero mantenía la opinión de que las fórmulas de tercera posición - expresadas en las socialdemocracias- no eran alternativas estables que pudieran alcanzar soluciones permanentes. Ahora bien, ¿no surgía acá una contradicción al reconocer la imposibilidad de soluciones intermedias, por un lado, y el señalamiento de que los modelos puros tampoco existían en la práctica, por el otro? ¿No se convertía también la Economía Social de Mercado en una alternativa intermedia o de tercera posición? La resolución de este conflicto aparente era explicada de esta manera por Alsogaray:

Las fórmulas de tercera posición pretenden ser estables en sí mismas y estar capacitadas para procurar soluciones ad hoc para cada uno de los problemas que se van presentando [...]. En cambio, la Economía Social de Mercado, si bien reconoce que en el estado actual en que se desenvuelve una comunidad existe una mezcla de procedimientos y de soluciones que se derivan de los dos principios fundamentales, sostiene que las soluciones no deben buscarse a través de procedimientos especiales para cada caso, sino que lo importante es procurar que se llegue a estas soluciones a través del libre juego de las fuerzas del mercado. Es decir, que la solución no provendrá de la combinación afortunada de procedimientos derivados de los dos principios alternativos sino que será una consecuencia de la puesta en marcha de los mecanismos del mercado.

Las «terceras posiciones» representan la búsqueda de un punto intermedio en el cual una mezcla de procedimientos que responden a filosofías opuestas conduciría supuestamente a las soluciones deseadas. La Economía Social de Mercado procura en cambio abandonar ese punto intermedio en que nos encontramos para avanzar tan firmemente como resulte posible hacia la aplicación de las leyes del mercado. [...]. Lo que importa para la Economía Social

116 Alsogaray (1969, p. 30). 
de Mercado es el movimiento en sí mismo y, por supuesto, el sentido en que se produce. El solo hecho de ponerse en marcha hacia la liberación de las fuerzas del Mercado ya significa comenzar a resolver los problemas. Cuanto más se avance en el sentido fijado más segura y rápidamente habrán de resolverse dichos problemas. ${ }^{117}$

De esta manera, Alsogaray definía conceptualmente lo que el denominaba el postulado de la tendencia: «Lo importante es determinar el sentido del movimiento, esto es, la dinámica del proceso para cuyo registro se necesitaría no ya una foto sino una película cinematográfica». ${ }^{118}$ Lo que los hombres que actúan en política debían lograr para la resolución de los problemas era la «fijación de una tendencia y no la búsqueda de una fórmula milagrosa». ${ }^{119}$ El objetivo era, sabiendo que nunca se alcanzaría a realizar el orden social en su forma pura, tender hacia ese modelo ideal mediante «la liberalización de las fuerzas del mercado». ${ }^{120}$ Alsogaray consideraba a la noción de tendencia una excelente guía para la acción del político ya que la aplicación de este concepto dinámico tendría las siguientes ventajas para esta actividad singular:

[...] permite actuar coherentemente en los casos prácticos que debe resolver a diario [...] le exime de buscar soluciones ad hoc para cada problema y de depender de un alto nivel de eficiencia de una burocracia siempre difícil de manejar. Le permite sustituir la obligación de hacer por la de dejar hacer. Le cambia el cuadro de sus responsabilidades: ya no necesita ser un experto en todos los temas, ya no debe estar programando una salida para cada uno de ellos, ya no experimenta la sensación angustiosa de que todo se demora porque él no puede ocuparse de esos mil problemas al mismo tiempo. Le basta con pensar una sola cosa: "¿Cómo hago para restablecer en el caso que estoy considerando el libre juego del mercado a efectos de que este último resuelva el problema?» Esta simple pregunta le fija el camino a seguir.

\footnotetext{
117 Alsogaray (1968, pp. 62-63).

118 Alsogaray (1969, p. 64).

119 Alsogaray (1989, p. 64)

120 Ibíd.
} 
La gran mayoría de las cuestiones prácticas puede resolverse conforme a esa norma $[\ldots]^{121}$

Alsogaray entendía, entonces, al postulado de la tendencia como una regla práctica al momento de tomar decisiones en el campo de la política. Y la alternativa que mejor expresaba dicho movimiento hacia un orden socioeconómico liberal era, según él, la Economía Social de Mercado:

La Economía Social de Mercado no es una fórmula mágica ni se basa en la aplicación de un modelo absoluto. Representa una tendencia hacia un estado de organización social que se considera deseable, al cual busca aproximarse en forma asintótica mediante técnicas y procedimientos compatibles con las libertades individuales y la dignidad de las personas [...]. No se trata ya de pasar de golpe de una situación determinada a la de un modelo ideal concebido en términos absolutos, ni tampoco de aplicar técnicas que alteren drásticamente todo el orden existente. Por el contrario, proceder conforme a una tendencia implica marchar hacia un objetivo con firmeza pero al mismo tiempo con flexibilidad para ir adaptándose a las distintas situaciones que se presentan. ${ }^{122}$

Por lo tanto, la Economía Social de Mercado no significaba una alternativa que rompiera de manera dramática y abrupta con el orden establecido sino una estrategia de adaptación a las nuevas situaciones que se irían creando, siempre avanzando firmemente en la sustitución y eliminación de los obstáculos que frenan la liberalización de las energías e iniciativas individuales.

IV

CONCLUSIONES

Las propuestas e ideas de Alsogaray fueron tildadas muchas veces - tanto desde el ámbito político como académico- de

\footnotetext{
121 Alsogaray (1989, pp. 68-69).

122 Alsogaray (1969, pp. 309-310).
} 
conservadoras, intervencionistas e incluso discordantes o incompatibles con las ideas mismas de la libertad. Tachado también de golpista, de representante de intereses económicos internacionales, de entusiasta antiperonista y adherente a la democracia calificada o restringida. Se le reconoció por su permanente oposición al populismo, representado por la inmensa mayoría de las fuerzas políticas del país; por la permanente aceptación del debate ante sus oponentes ideológicos y políticos; por el rechazo a las propuestas demagógicas que mayoritariamente compartieron los políticos de su época; por el componente didáctico que siempre empleaba tanto en sus discursos públicos como en sus intervenciones en los medios de comunicación; por la identificación permanente de los problemas económicos y políticos del país seguido de la correspondiente propuesta o medida concreta orientadas a solucionar los mismos. Mayoritariamente, tanto los opositores como los partidarios de su figura y propuestas, no dejaron nunca de reconocerle a Alsogaray la coherencia, admiración y fidelidad hacia el mismo conjunto de ideas que sostuvo durante toda su vida pública, aquellas que estaban representadas fundamentalmente en el pensamiento de Rueff, Röpke, Hayek y Erhard.

Alsogaray estaba convencido de que la causa del progresivo empeoramiento de la Argentina había sido la instauración, entre la tercera y cuarta década del siglo XX, del sistema económico caracterizado por el estatismo, el intervencionismo y el financiamiento inflacionario de dicho orden socioeconómico. El Ingeniero observaba que el mantenimiento de dicho estado de cosas se debía tanto a la clase dirigente del país como a la ciudadanía en su conjunto. En el caso de la clase dirigente, el Ingeniero la imputaba la falta de una ideología clara y definida en relación con aquellos gobiernos y dirigentes que se oponían al sistema económico vigente, la ignorancia para comprender las causas fundamentales de los problemas y la incapacidad para resolverlos y, por último, la ineptitud para gobernar el país. A la ciudadanía la responsabilizaba por su falta de conocimientos respecto a las causas de la creación de la riqueza y de los factores que conducían al empobrecimiento del país. Para Alsogaray el esquema estatista e intervencionista que se había establecido en la Argentina tenía como consecuencia inherente al sistema un creciente control totalitario 
sobre la economía y, consecutivamente, una progresiva limitación de las libertades individuales. En consecuencia, Alsogaray concentró sus esfuerzos en luchar a favor del cambio del orden socioeconómico fundamentado en lo que él llamaba «liberalismo moderno» o lo que se conocía en el mundo occidental como Economía Social de Mercado. Las acciones para lograr aquella meta las ejecutó en diversos planos: fundando partidos políticos, participando en los gobiernos en cargos relevantes, haciendo pública su opinión en todos los medios de comunicación y foros disponibles, publicando libros, creando un instituto dedicado al estudio y análisis de políticas públicas, etc.

Son varios los temas por los cuales se le reconoce a Alsogaray: la prédica a favor de la estabilidad monetaria, la necesidad de mantener las cuentas públicas equilibradas y una estructura estatal no sobredimensionada, la inconveniencia de analizar la realidad argentina bajo la perspectiva peronista-antiperonista y la necesidad de hacerlo según la naturaleza del orden socio económico (sistemas totalitarios, híbridos o abiertos), el repudio a las «democracias de masas» o ilimitadas y el rechazo a los gobiernos que pusieran en peligro los principios de la Constitución nacional con independencia de que aquellos fueran civiles o militares.

Encontramos en Alsogaray, en síntesis, una permanente voluntad de exponer ante la ciudadanía la inequívoca relación entre las ideas y la acción; también una persistente vocación de divulgar lo que para él eran las ideas correctas y desenmascarar lo que consideraba doctrinas falaces. Alsogaray luchó constantemente para reducir en la Argentina la influencia de las ideas populistas, estatistas e intervencionistas que mayoritariamente predominaban tanto en la opinión pública como en la clase dirigente de la política del país.

\section{REFERENCIAS BIBLIOGRÁFICAS}

Academia Nacional de Ciencias Económicas (1969): «Teoría y práctica en la acción económica». Conferencia de incorporación de Alsogaray como Académico de número de la Academia Nacional de Ciencias Económicas. Buenos Aires. 
Alsogaray, Á. (1968): Bases para la acción política futura. Editorial Atlántida, Buenos Aires.

- (1969): Política y economía en latinoamérica. Editorial Atlántida, Buenos Aires.

- (1989): Bases liberales para un programa de gobierno (1989-1995). Editorial Planeta, Buenos Aires.

- (1993): Experiencias de 50 años de política y economía argentina. Editorial Planeta, Buenos Aires.

CERdÁ OMiste, E.: «La reforma económica alemana de 1948». Libertas, N.o 6, Mayo de 1987. Año IV.

Cerro, A.M. y Meloni, O. (2003): «Crisis in Argentina: 1823-2002. The same old story», XXXVIII Reunión Anual Asociación Argentina de Economía Política, Mendoza.

CoRTés CONDE, R. (1997): La economía argentina en el largo plazo (siglos XIX y XX). Editorial Sudamericana-Universidad de San Andrés, Buenos Aires.

De PABLo, J.C. (1977): Los economistas y la economía argentina. Ediciones Macchi, Buenos Aires.

- (2005): La economía argentina en la segunda mitad del siglo XX, tomo II, Editorial La Ley, Buenos Aires.

- (2010): 200 años de economía argentina. Ediciones B, Buenos Aires.

Diario La Nación, Buenos Aires, Argentina.

EbeLING, R. (2003): «The limits of economic policy: the Austrian economist and the German ORDO liberals». Austrian Economics and the Political Economy of Freedom. Edward Elgar, Cheltenham.

Ebenstein, A. (2001): Friedrich Hayek: A Biography. Palgrave, New York.

Entrevista a María Julia Alsogaray, 31 de julio y 3 de octubre de 2007, Buenos Aires.

EUCKEN, W. (1962): «El problema político de la ordenación». La economía de mercado. Sociedad de Estudios y Publicaciones, Madrid.

HAYEK, F. (1975): Los fundamentos de la libertad, 4. a edición, Unión Editorial, Madrid.

- (1976): Derecho, legislación y libertad. El orden político de una sociedad libre. Volumen 3, Unión Editorial, Madrid. 
- (1985): Democracia, justicia y socialismo. 2. edición, Unión Editorial, Madrid.

- (1990): Camino de servidumbre, 3.a edición, Alianza Editorial, Madrid.

- (1997): Hayek sobre Hayek, Un diálogo autobiográfico, Obras Completas, Volumen I, Unión Editorial, Madrid.

InSTITUTO DE LA ECONOMía Social DE MerCAdo (1984): «Seminario de presupuesto, inflación y deuda externa». Editado por Instituto de la Economía Social de Mercado, Buenos Aires.

LAMPERT, H. (1990): El orden económico y social de la República Federal de Alemania. Unión Editorial, Madrid.

Müller-Armack, A. (1963): Economía dirigida y economía de mercado. Sociedad de Estudios y Publicaciones, Madrid.

[NuEVA FuERZA] (1972): «Cuarenta preguntas formuladas al ingeniero Álvaro Alsogaray y sus respuestas», Buenos Aires.

Noticias, 31 de enero de 2004, Editorial Perfil, Buenos Aires, Argentina.

RöpKe, W. (1949): Civitas Humana. Cuestiones fundamentales en la reforma de la sociedad y de la economía. Biblioteca de la Ciencia económica, Traducción de la 3. a edición, Madrid.

RuefF, J. (1979): Theorie Monetaire, Libraire Plon, Paris.

Sebreli, J.J. (2004): Crítica de las ideas políticas argentinas. Editorial Sudamericana, Buenos Aires.

SOLANET, M. (2006): La hiperinflación del 89. Editorial Lumiere, Buenos Aires.

Somos, 25 de noviembre de 1977, Editorial Atlántida, Buenos Aires.

Todo es Historia, diciembre de 1995, n. ․ 341, Editorial Todo es Historia, Buenos Aires.

Tribuna Cívica, 30 de noviembre de 1965, n.ํㅜ 65, Segunda Época, Buenos Aires.

Unión del Centro Democrático (1982): «Orígenes del partido y documentos iniciales relacionados con su fundación», Buenos Aires.

Unión del Centro Democrático (1983): «Bases Doctrinarias de la Unión del Centro Democrático», Buenos Aires. 